\title{
The Combined Effect of STAT3 and NF-Kb Inhibitors (The Last Links of the Cholinergic Anti-Inflammatory Pathway) on Mouse Mortality and Blood Concentration of Proinflammatory Cytokines in Sepsis
}

\author{
Zabrodskii PF* \\ Saratov Medical University “REAVIZ”, Russia
}

*Corresponding author: Pavel Frantzevich Zabrodskii, Saratov Medical University "REAVIZ", Saratov, Russia, Tel: 845222-76-25; Email: pfzabrodsky@gmail.com

\section{Research Article}

Volume 2 Issue 1

Received Date: January 03, 2020

Published Date: January 23, 2020

DOI: $10.23880 /$ aii-16000111

\section{Abstract}

Experiments on random-bred albino mice showed that the inhibitor of the transcription factor STAT3 (S3I-201) and the NF-Kb inhibitor (BAY 11-7082) significantly reduced the mortality of mice from experimental sepsis (intraperitoneal administration of E. coli) in 4 and $24 \mathrm{~h}$ after modeling by reducing blood levels of Proinflammatory cytokines TNF $\alpha$, IL-1 $\beta$, and IL-6. The combined actions of STAT3 and NF-Kb inhibitors (the last links of the cholinergic anti-inflammatory pathway) have an additive effect.

Keywords: Cholinergic Anti-Inflammatory Pathway; Proinflammatory Cytokines; Sepsis; STAT3 Inhibitor; NF-Kb Inhibitor

\section{Introduction}

Mortality from sepsis, depending on various factors, ranges from 12 to $60 \%$ of all deaths associated with diseases and their complications [1], and it is noted as an increase in the number of cases of sepsis, and mortality rate from it [25]. For the first time in 1987, it was found that cholinergic stimulation significantly reduces the mortality of albino mice from sepsis [6], and later proved the feasibility of using cholinomimetics for emergency activation of the body's antimicrobial resistance in sepsis [7]. The cholinergic anti-inflammatory mechanism was named after the study of its implementation on the organismic [6], cellular and subcellular levels in 2000 as the "cholinergic antiinflammatory pathway" [6-8].

Currently, there is a great interest of researchers associated with the study of the possibility of reducing mortality in sepsis and various pathological processes by stimulating or inhibiting various elements of the cholinergic anti-inflammatory pathway $[3-5,9,10]$, in particular, the possibility of achieving a therapeutic effect while inhibiting of NF-Kb and STAT3 transcription factor $[9,11,12]$ (the last links of the cholinergic anti-inflammatory pathway) [8].

\section{Aim of the Study}

The aim of the study was to assess the effect of the inhibitor of the STAT3 transcription factor (S3I-201 drug) and the NF-Kb inhibitor (BAY 11-7082), as well as their combined effect (the last links of the cholinergic antiinflammatory pathway) on the mortality of mice in the early phase of sepsis caused by experimental peritonitis, and the content of Proinflammatory cytokines TNF - $\alpha$, IL-1 $\beta$, IL-6 in the blood. 


\section{Materials and Methods}

The experiments were performed on random-bred albino mice of both sexes weighing 18-22g. The control group of mice (control group 1, $\mathrm{n}=8$ ) received intraperitoneally $2.0 \mathrm{ml}$ of isotonic sodium chloride solution (saline) 10-15 minutes after the last intraperitoneal the introduction of $0.5 \mathrm{ml}$ of $0.05 \%$ aqueous solution of dimethyl sulfoxide-DMSO (Sigma-Aldrich), which was used daily for 4 days. The second group of mice (control group 2, $\mathrm{n}=47$ ) was injected for 4 days with $0.5 \mathrm{ml}$ of a $0.05 \%$ aqueous solution of DMSO (i.p., once daily). 30-45 min after administration of this solution, mice in this group received (i.p.,) $2.5 \times 109$ CFUs diurnal culture of E. coli in $2.0 \mathrm{ml}$ of saline (sepsis modeling) [4-7]. The third group ( $\mathrm{n}=25)$ was administered (i.p., once daily) for 4 days STAT3 inhibitor (S3I-201-2-Hydroxy-4-[[[[(4-methylphenyl) sulfonyl] oxy] acetyl] amino]-benzoic acid) (Sigma-Aldrich) at a dose of $5 \mathrm{mg} / \mathrm{kg}$ in $0.5 \mathrm{ml}$ of a $0.05 \%$ aqueous solution of DMSO [11]. The fourth group $(\mathrm{n}=33)$ was administered (i.p., a single dose) the NF-Kb inhibitor BAY 11-7082-(E)-3(4-Methylphenylsulfonyl)-2-propenenitrile-(Sigma-Aldrich) at a dose of $10 \mathrm{mg} / \mathrm{kg}$ in $0.5 \mathrm{ml}$ of a $1 \%$ aqueous solution of DMSO (Sigma-Aldrich) [5]. Prior to the administration of the $\mathrm{NF}-\mathrm{Kb}$ inhibitor this group of mice received $0.5 \mathrm{ml}$ of a $0.05 \%$ aqueous solution of DMSO for 3 days (i.p., once daily). In the 5th group $(n=25)$ the STAT3 inhibitor (S3I-201) was administered in combination with the NF-Kb BAY inhibitor (11-7082). NF-Kb inhibitor was administered 10-15 minutes after the last injection of the STAT3 inhibitor. In groups 3 and 5, after 30-45 minutes after the administration of drugs, sepsis was modeled (in group 3, after 30-45 minutes after the last injection of the drug).

The mortality of mice (groups 2-3) was recorded after 4 and $24 \mathrm{~h}$ after the sepsis modeling. The concentration of TNF- $\alpha$, IL1 $\beta$ and IL- 6 were measured in the blood plasma of all groups of mice (groups 1-5) using by ELISA (My Bio Source) according to manufacturer's instructions. Determination the concentrations of Proinflammatory cytokines used monoclonal antibodies My Bio Source (cat.NMBS494184, MBS494492, MBS335516 for TNF- $\alpha$, IL-1 $\beta$, and IL-6, respectively). Blood for research was taken from the retroorbital venous sinus. The obtained data were processed statistically using Student's t-test (program STATISTICA 6.0).

\section{Results}

The STAT3 inhibitor (S3I-201) caused a decrease in the mortality of mice 4 hours after the administration of the daily culture of $E$. coli (sepsis modeling) compared to the control group 2 (sepsis) by 2.4 times (by $28.1 \%-\mathrm{p}<0.05$ ), and after 24hours-by 1.4 times (by $24.9 \%$-p<0.05). The NF-Kb inhibitor reduced mortality from sepsis after 4 and 24 hours after its modeling compared with group 2, respectively, 2.0 times ( $\mathrm{p}<0.05$ ) (by 24.7\%) and 1.8 times (by 35,4\%) (p<0.05). The administration of the STAT3 inhibitor in combination with the NF-Kb inhibitor caused an additive effect. Thus, the mortality of mice compared with the control after 4 and 24hours after the administration of E. coli compared with the control (group 2) decreased, respectively, by 3.1 times (by $32.9 \%)(\mathrm{p}<0.05)$ and by 2, 9 times (by $52.9 \%)(\mathrm{p}<0.05)$ (Table 1).

\begin{tabular}{|c|c|c|}
\hline \multirow{2}{*}{ Group (series of experiments) } & \multicolumn{2}{|c|}{ Term study of Mortality After the Introduction of $\boldsymbol{E}$. coli, $\mathbf{h}$} \\
\cline { 2 - 3 } & $\mathbf{4 ~ h}$ & $\mathbf{2 4} \mathbf{~ h}$ \\
\hline 2nd control group (sepsis; $\mathrm{n}=47$ ) & $48.9 \pm 7.3$ & $80.9 \pm 5.7$ \\
\hline 3rd (STAT3 inhibitor - S3I-201; $\mathrm{n}=25$ ) & $20.0 \pm 8.0^{*}$ & $56.0 \pm 9.9^{*}$ \\
\hline 4th (NF-Kb inhibitor BAY 11-7082; $\mathrm{n}=33$ ) & $24.2 \pm 7.5^{*}$ & $45.5 \pm 8.7^{*}$ \\
\hline 5th (STAT3 inhibitor + NF-Kb inhibitor; $\mathrm{n}=25)$ & $16.0 \pm 7.3^{*}$ & $28.0 \pm 9.0^{* *}$ \\
\hline
\end{tabular}

${ }^{*}$-p $<0.05$ as compared to group 2); ** $-\mathrm{p}<0.05$ in comparison with the control group 2 and group 3.

Table 1: Effect of STAT3 inhibitor (S3I-201, $5 \mathrm{mg} / \mathrm{kg}$, once daily for 4 days) and NF-Kb inhibitor (BAY 11-7082, 10mg/kg, and a single dose) and their combined effect on mice mortality in sepsis, \% (M $\pm m$ ).

The combined effect of the drugs compared to mortality with only STAT3 inhibitor or NF-Kb inhibitor caused a statistically insignificant reduction of the studied parameter after 4 hours, respectively, by 1.3 times (by $4.0 \%$-p $>0.05$ ) and by 1.5 times (by $8.2 \%$-p>0.05), After 24 hours, a significant effect of the combination of drugs was observed compared with the effect of only the STAT3 inhibitor (a decrease in mortality by 2.0 times $(28.0 \%-p<0.05)$, respectively. The obtained data show that the combined effect of the STAT3 and the NF-Kb inhibitors exceeds the effect of the STAT3 inhibitor, and insignificantly ( $p>0.05)$ the effect of the NF-Kb inhibitor.

The concentration of cytokines TNF- $\alpha$, IL- $1 \beta$ and IL- 6 after the sepsis modeling (control group 2) in the blood of mice after $4 \mathrm{~h}$ compared with the control group 1 (intact animals), increased respectively to $19.7 ; 19.8$ and 59.3 times $(\mathrm{p}<0.05)$, and after 24 hours, the content of these cytokines compared to their level after $4 \mathrm{~h}$ decreased, respectively, to $23.0 ; 4.4$ and 8.4 times $(\mathrm{p}<0.05)$. The content of IL-1 $\beta$ 
and IL- 6 after $24 \mathrm{~h}$ remained higher than in group 1 by 1.6 times $(p>0.05)$ and 3.2 times $(p<0.05)$, respectively, and the concentration of TNF- $\alpha$ in groups 1 and 2 did not differ significantly (Table 2).

\begin{tabular}{|c|c|c|c|c|c|c|}
\hline \multirow{2}{*}{ Series of Experiments } & \multicolumn{2}{|c|}{ ФнО } & \multicolumn{2}{c|}{ ил1 $\boldsymbol{\beta}$} & \multicolumn{2}{c|}{ ил-6 } \\
\cline { 2 - 7 } & $\mathbf{4}$ & $\mathbf{2 4}$ & $\mathbf{4}$ & $\mathbf{2 4}$ & $\mathbf{4}$ & $\mathbf{2 4}$ \\
\hline Control group 1 & $49 \pm 6$ & $38 \pm 5$ & $31 \pm 5$ & $33 \pm 6$ & $35 \pm 7$ & $25 \pm 4$ \\
\hline Sepsis (control group 2) & $966 \pm 105 \mathrm{a}$ & $42 \pm 8 \mathrm{c}$ & $615 \pm 78 \mathrm{a}$ & $141 \pm 25 \mathrm{ac}$ & $2077 \pm 262 \mathrm{a}$ & $246 \pm 30 \mathrm{ac}$ \\
\hline STAT3 inhibitor-S3I-201 (group 3) & $174 \pm 23 \mathrm{ab}$ & $34 \pm 7 \mathrm{c}$ & $160 \pm 25 \mathrm{ab}$ & $52 \pm 10 \mathrm{bc}$ & $286 \pm 32 \mathrm{ab}$ & $81 \pm 13 \mathrm{abc}$ \\
\hline NF-Kb inhibitor-BAY 11-7082 (group 4) & $137 \pm 20 \mathrm{ab}$ & $45 \pm 8 \mathrm{c}$ & $141 \pm 26 \mathrm{ab}$ & $60 \pm 9 \mathrm{abc}$ & $233 \pm 30 \mathrm{ab}$ & $70 \pm 14 \mathrm{abc}$ \\
\hline STAT3 inhibitor+ NF-kb inhibitor (group 5) & $108 \pm 17 \mathrm{ab} \mathrm{d}$ & $50 \pm 8 \mathrm{c}$ & $122 \pm 21 \mathrm{ab}$ & $35 \pm 6 \mathrm{abc}$ & $191 \pm 27 \mathrm{abd}$ & $45 \pm 7 \mathrm{abcd}$ \\
\hline
\end{tabular}

Note: 4 and 24-time after modeling of sepsis, ; $^{\text {a }}$-p $<0.05$ compared to control (group 1 ); ${ }^{\mathrm{b}}$-p $<0.05$ compared with corresponding parameter for sepsis (control group 2); ${ }^{\mathrm{c}}$-p $<0.05$ compared with parameter after $4 \mathrm{~h}$; ${ }^{\mathrm{d}}$-p $<0.05$-in comparison with group 3.

Table 2: Effect of STAT3 inhibitor (S3I-201, 5mg/kg, once daily for 4 days) and NF-Kb inhibitor (BAY 11-7082, 10mg/kg, a single dose) and their combined effect on the concentration of Proinflammatory cytokines in blood of mice after modeling of sepsis, $\mathrm{pg} / \mathrm{ml}(\mathrm{M} \pm \mathrm{m} ; \mathrm{n}=7-8)$.

The NF-Kb inhibitor (BAY 11-7082) $4 \mathrm{~h}$ after sepsis modeling reduced the blood levels of TNF- $\alpha$, IL- $1 \beta$ and IL- 6 (group 4) compared to the control group 2, respectively, by $7.0 ; 4.4$ and 8.9 times $(\mathrm{p}<0.05)$. After 24 hours, the content of these cytokines compared with their level after 4 hours decreased, respectively, by 3.0; 2.4 and 3.3 times $(\mathrm{p}<0.05)$. The concentrations of IL- $1 \beta$ and IL-6 statistically significantly $(\mathrm{p}<0.05)$ exceeded those of the control group 1 by 1.8 and 7.8 times $(\mathrm{p}<0.05)$, respectively, and compared to the parameters of group 2 , the content IL- $1 \beta$ and IL- 6 were reduced by 2.4 and 3.5 times, respectively $(p<0.05)$. The value of TNF- $\alpha$ was not significantly different from the levels in groups 1 and after $24 \mathrm{~h}$ after the sepsis modeling.

The concentrations of TNF- $\alpha$, IL- $1 \beta$ and IL- 6 in group 5 (combined effect of STAT3 and NF-Kb inhibitors) compared with parameters of group 3 (effect of STAT3 inhibitor) $4 \mathrm{~h}$ after sepsis modeling were lower respectively by $1.6(\mathrm{p}<0.05) ; 1.3$ $(p>0.05)$ and 1.5 times $(p<0.05)$, and after $24 \mathrm{~h}$ the levels of IL- $1 \beta$ and IL- 6 were less than the corresponding values in the group of 3 by $1.5(\mathrm{p}>0,05)$ and by 1.8 times $(\mathrm{p}<0.05)$.

The blood levels of TNF- $\alpha$, IL-1 $\beta$, and IL- 6 in group 5 compared with those of group 4 (the effect of NF-Kb inhibitor) did not differ significantly $(\mathrm{p}>0.05)$ after $4 \mathrm{~h}$ after the sepsis modeling, and after $24 \mathrm{~h}$ IL-1 $\beta$ and IL- 6 levels were less than the corresponding values in group 4 by $1.7(\mathrm{p}<0.05)$ and by 1.6 times ( $p>0.05)$.

The blood concentrations of TNF- $\alpha$, IL- $1 \beta$ and IL- 6 in group 5 with a combined effect of STAT3 inhibitor (S3I-201) and of NF-Kb inhibitor (BAY 11-7082) $4 \mathrm{~h}$ after modeling sepsis compared with the control group 2 (sepsis without the use of drugs) decreased, respectively, by 8.9; 5.0 and 5.5 times $(p<0.05)$. The content of cytokines IL- $1 \beta$ and IL- 6 significantly $(\mathrm{p}<0.05)$ exceeded the corresponding parameters of group
1. The concentration of pro-inflammatory cytokines after $24 \mathrm{~h}$ after modeling sepsis significantly decreased $(\mathrm{p}<0.05)$ compared with these parameters after $4 \mathrm{~h}$. The content of TNF- $\alpha$ did not differ from those in groups 1-4, and the levels of IL- $1 \beta$ and IL- 6 remained lower than the values in group 2 by 4.0 and by 5.5 times $(\mathrm{p}<0.05)$, respectively.

The data obtained suggest that the combined action of STAT3 inhibitor and NF-Kb inhibitor (the last links of the cholinergic anti-inflammatory pathway) causes an additive effect.

\section{Discussion}

The cholinergic anti-inflammatory mechanism ("cholinergic anti-inflammatory pathway") [6,7,13-15], includes: acetylcholine $\mathrm{m}$-acetyl cholinergic receptor type 1 (m1AChR) activation of the brain, modulating the immunoregulatory function of the vagus nerve $[4,5,8,13]$; excitation of efferent fibers $n$. vagus; effect of acetylcholine on $a 7 n$-acetylcholine receptors ( $\alpha 7 n A C h R)$ of cells of the macrophage-monocytic system (MMS) $[3,5,15]$. The occurrence of anti-inflammatory effect in cells of MMS is provided by JAK2 kinase; STAT3 transcription factor; NF$\kappa \mathrm{B}$ transcription factor $[4,5,8,13,14]$. These effects lead to a decrease in mortality from sepsis due to the reduction of the production of pro-inflammatory cytokines TNF- $a$, protein B1-HMGB1, macrophage-inflammatory protein-2-MIP-2, interleukins-IL-1 $\beta$, IL-6 [5,7,8,13,14]. We have shown a decrease in the mortality of mice from sepsis after activation of $a 7 \mathrm{nAChRs}[3,4]$, m1AChRs [4], a 2-adrenoreceptors ( $\beta$ 2ARs) [5], inhibition of NF- $K$ B factor [5], and also their combined action was evaluated.

The transcription factor NF-Kb modulates the synthesis of pro-inflammatory cytokines involved in development of 
sepsis. Signal pathways initiated by Toll-like receptors (TLR2 and TLR4) to which bacterial products bind, in particular, $E$. coli lipopolysaccharide, lead to enhanced transcription of genes responsible for expression of cytokines, chemokines, adhesion molecules, apoptotic factors and other mediators of inflammatory response associated with sepsis [5].

\section{Conclusion}

The STAT3 inhibitor (S3I-201) and the NF-Kb inhibitor (BAY 11-7082) the last links of the cholinergic antiinflammatory pathway-reduce the mortality of mice, the content of pro-inflammatory cytokines TNF- $\alpha$, IL-1 $\beta$ and IL-6 in the blood in sepsis, and their combined action causes an additive effect.

\section{References}

1. Lin JN, Tsai YS, Lai CH, Chen YH, Tsai SS, et al. (2009) Risk factors for mortality of bacteremic patients in the emergency department. Acad Emerg Med 16(8): 749755.

2. Martin GS (2012) Sepsis, severe sepsis and septic shock: changes in incidence, pathogens and outcomes. Expert Rev Anti Infect Ther 10(6): 701-706.

3. Zabrodskii PF, Gromov MS, Maslyakov VV (2015) Effect of $\alpha 7 n$-acetylcholine receptor activation and antibodies to TNF- $\alpha$ on mortality of mice and concentration of Proinflammatory cytokines during early stage of sepsis. Bull Eksp Biol Med 159(6): 740-742.

4. Zabrodskii PF, Gromov MS, Maslyakov VV (2017) Combined Effects of M1 Muscarinic Acetylcholine Receptor Agonist TBPB and $\alpha 7 n$-Acetylcholine Receptor Activator GTS-21 on Mouse Mortality and Blood Concentration of Proinflammatory Cytokines in Sepsis. Bull Eksp Biol Med 162(6): 750-753.

5. Zabrodskii PF, Gromov MS, Maslyakov VV (2018) Combined effect of NF-kB inhibitor and $\beta 2$ Adrenoreceptor agonist on mouse mortality and blood concentration of proinflammatory cytokines in sepsis. Bull Exp Biol Med 165(4): 445-448.

6. Zabrodskii PF (1987) Effect of armin on nonspecific resistance factors of the body and on the primary humoral immune response. Farmakol Toksikol 50(1): 57-60.

7. Zabrodskii PF (1995) Variation in ant infectious nonspecific resistance of the organism caused by cholinergic stimulation. Bull Eksp Biol Med 120(2): 809-811.

8. Borovikova LV, Ivanova $S$, Zhang $M$, Yang $H$, Botchkina $G$, et al. (2000) Vagus nerve stimulation attenuates the systemic inflammatory response to endotoxin. Nature 405(6785): 458-462.

9. Wang Z, Li J, Xiao W, Long J, Zhang H (2018) The STAT3 inhibitor S3I-201 suppresses fibrogenesis and angiogenesis in liver fibrosis. Lab Invest 98(12): 16001613.

10. Zila I, Mokra D, Kopincova J, Kolomaznik M, Javorka M, et al. (2017) Vagal-immune interactions involved in cholinergic anti-inflammatory pathway. Physiol Res 66 (S2): 139-145.

11. Park JW, Han CR, Zhao L, Willingham MC, Cheng SY (2016) Inhibition of STAT3 activity delays obesity-induced thyroid carcinogenesis in a mouse model. Endocr Relat Cancer 23(1): 53-63.

12. Zhao J, Yu H, Liu Y, Gibson SA, Yan Z, et al. (2016) Protective effect of suppressing STAT3 activity in LPSinduced acute lung injury. Am J Physiol Lung Cell Mol Physiol 311(5): 868-880.

13. Gallowitsch Puerta M, Pavlov VA (2007) Neuro-immune interactions via the cholinergic anti-inflammatory pathway. Life Sci 80(24-25): 2325-2329.

14. Pavlov VA, Wang H, Czura CJ, Friedman SG, Tracey KJ (2003) The cholinergic anti-inflammatory pathway: a missing link in neuroimmunomodulation. Mol Med 9(58): $125-134$.

15. Wang H, Yu M, Ochani M, Amella CA, Tanovic M, et al. (2003) Nicotinic acetylcholine receptor alpha7 subunit is an essential regulator of inflammation. Nature 421(6921): 384-388. 